\title{
Biomechanical Statistical Model for the Accuracy of the Forehand Smash Stroke in Higher Levels of Table Tennis
}

\author{
Mahasen Hassanein Alwan ${ }^{1}$
}

\author{
${ }^{1}$ Assistant Professor at the Sports Training and Motor Sciences Department, Faculty of Physical Education for Girls, Alexandria \\ University, Egypt
}

\begin{abstract}
The research aims to improve the accuracy of the forehand smash stroke in higher levels of table tennis through: Designing and standardizing the test of the accuracy of the forehand smash stroke in higher levels of table tennis, Recognizing the relationship between some of the biomechanical indicators and the degree of accuracy at the moment of hitting the ball, Extracting a biomechanical statistical model in light of predicting the equation of the accuracy of the smash stroke at the moment of hitting the ball. The sample was selected by the Propulsive Sampling Technique. 13 table tennis players from Smouha and Alexandria Sporting Club "Sporting" were selected. The players were divided into 10 players to control the test and 3 players to conduct the video record and the biomechanical analysis. 3 excellent players in the forehand smash stroke were selected to record their performance by a video camera. The researcher reached the following conclusions: (A) the proposed test is used to measure the accuracy of the smash stroke. (B) The biomechanical statistical model that concluded according to the degree of correlation:
\end{abstract}

The accuracy degree of performance $=$ Constant + Stepwise Regression of variable $\times$ average resultant of variable

Keywords: Statistical Model, Forehand Smash, Table Tennis, Biomechanical Indicators

\section{Introduction and Research Problem}

$\mathrm{T}$ The mechanical principles of the motor performance are an important component that should be used in planning the training process to make it more effective and successful. The biomechanical analysis is one of the most important means to evaluate training programs.

Also, determining the biomechanical principles and foundations of the technical performance is considered as the first step towards applying of the basic mechanical laws on the human body movements. This contributes in improving the technical sports performance.

The biomechanical statistical model is one of the most forceful methods of the biomechanics researches and the progress in the predictive operations and the evolution of technical performance is thanks to the biomechanical statistical model.

The standardized tests that are constructed on samples represent the community; contribute in helping trainers to raise the efficiency of the training process. Through the technical performance of the high levels players; we can put an ideal model for the outstanding performance. (11 :137)

The forehand smash stroke is considered as one of the most effective offensive strokes in this sport and players can win through it. This stroke is a very strong straight shot which has speed and force. This stroke distinguishes between a player and another and it puts the opponent it in a state of confusion. $(9: 10)(4: 15)$

The moment of hitting the ball is the most important moment in achieving the aim of this stroke. (3: 67)

The importance of mastering the smash stroke appears through the previous studies like Amira Ahmed (2009) (1), Marinovic (2004) (7) through the Open World Championship in 2004 in Egypt. The most important results of this study are: the percentage of using this skill was $66 \%$ for foreigners, and $40 \%$ for Egyptians. The percentage of achieving a direct point from this skill reaches $80 \%$ for foreigners and $35 \%$ for Egyptians. So, the researcher made this study to identify the biomechanical indicators that control the accuracy of the moment of hitting the ball.

The researcher reviewed the previous studies of table tennis and she did not find within the limits of her knowledge any study determines the places on the table that are more effective in achieving a direct and fast point, therefore, the researcher conducted this study in order to identify the most places that help in achieving a quick, direct and fast points. The researcher found that the percentage of falling the ball near the end line and achieving a direct point is $70 \%$ of the total smash strokes with the front side of the racket, also $20 \%$ of the balls 
were in the sideline, the places where it is difficult and confused to the opponent, while $10 \%$ of the balls falling in different areas on the table. These results were on the foreign players only. Attachment (2)

Within the limits of the researcher's knowledge of any of the previous studies; she found that no study dealt with the biomechanical variables of the used arm and the variables of the ball and their effect in directing the ball towards the hardest place on the table to achieve a fast and direct point. So, the researcher designed a test to measure the accuracy to put objective criteria to evaluate the performance of the players' level. So, this research may be used in the field of training and guiding the players to reach high levels in table tennis

\section{Aim of the Research}

The research aims to improve the accuracy of the forehand smash stroke in higher levels of table tennis through:

1. Designing and standardizing the test of the accuracy of the forehand smash stroke in higher levels of table tennis.

2. Recognizing the relationship between some of the biomechanical indicators and the degree of accuracy at the moment of hitting the ball.

3. Extracting a biomechanical statistical model in light of predicting the equation of the accuracy of the smash stroke at the moment of hitting the ball.

\section{Material and Methods}

1. The researcher used the descriptive survey method based on the biomechanical analysis, because of its appropriateness of the nature of the research.

2. This study was conducted in the period from $10 / 9 / 2012$ to 30/9/2012, in the Faculty of Physical Education For men - Alexandria University.

3. The sample was selected by the Propulsive Sampling Technique. 13 table tennis players from Smouha and Alexandria Sporting Club "Sporting" were selected. The players were divided into 10 players to standardize the test and 3 players to conduct the video recording and the biomechanical analysis. 3 excellent players in the forehand smash stroke were selected by the Propulsive Sampling in accordance with the following conditions: (a) High Levels Players.

(b) Players are registered in the Egyptian Federation of Table Tennis

(c) Performance with the Right Arm.

Their main characteristics: Average of $($ Age $=18.583$ year, height $=175 \mathrm{~cm}$, weight $=74.667 \mathrm{~kg}$, No. of training years $=7.333$ year, and accuracy of stroke $=7.042$ degree)

Tools of Data Collection:

- Analysis Matches Form.

- Experts Form.

- Accuracy Test of Smash Stroke.

- Television Filming

- Biomechanical Analysis Program.

\section{First, Special Procedures of the Accuracy Test of forehand Smash Stroke:}

The researcher reviewed the tests of the forehand smash stroke in table tennis which in scientific references, previous studies, internet. Also, she consulted experts. Through the researcher's experience in the field of table tennis training; she found that there is a need for a new objective assessment in line with the modern requirements of table tennis. This encouraged the researcher to design a test to measure the accuracy of the forehand smash stroke according to scientific good conditions. (11: 138)

Steps to Design the Test: After defining the goal of the test; the researcher did the following:

\section{Designing the test}

2. Drafting specifications and test conditions

3. Reviewing the tests on the experts and modifying the test

4. Initial experiment of the test

5. The test in its final design

6. Standardizing the test 


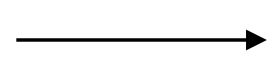

$152.5 \mathrm{~cm}$

$\leftarrow 30 \mathrm{~cm} . \rightarrow \quad \rightarrow \quad 92.5 \mathrm{CM} \leftarrow \quad \leftarrow 30 \mathrm{~cm} . \rightarrow$

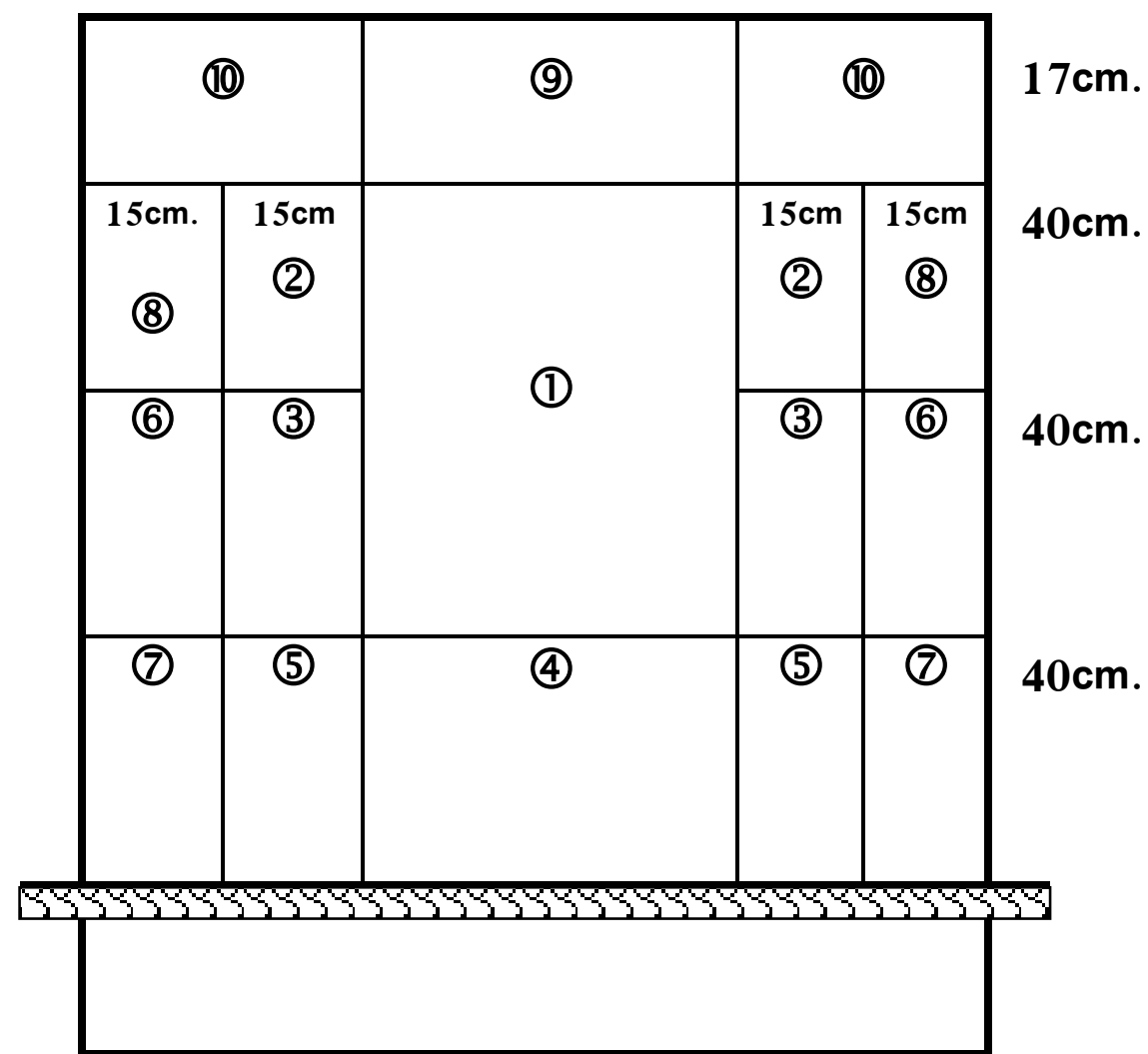

The value of the calculated $\mathrm{T}$ test of the differences between the two groups in the test of directing the ball is 4.839 and this value is significant at a level of 0.05 . The validity factor in the test is 0.868 . This confirms that accuracy test is discriminatory, and it measures what it was designed for.

The researcher tried to get the reliability coefficient after a week. The correlation coefficient between the first and second means was calculated.
The reliability coefficient is 0.911 , which confirms that the test of the degree of the accuracy of directing the ball is reliable and it gives the same results in the case of retesting in the same conditions.

Devices and tools of recording the test with the camera video:

A video camera at 125 cadre / s with considering requirements and procedures of filming. $(8: 2$ ، 3$)$ 
Figure (1)

Figure for hand smash stroke in table tennis

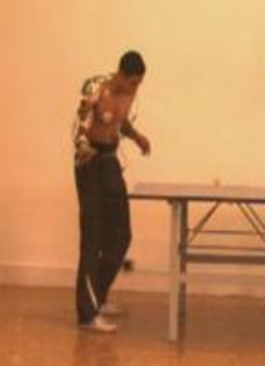

1

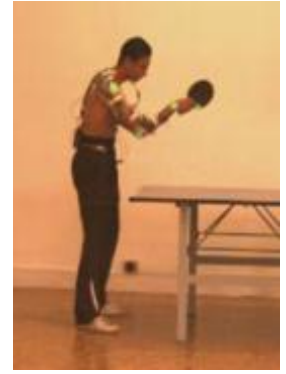

6

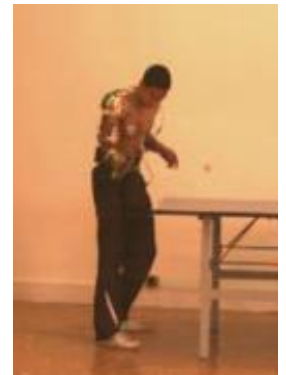

2

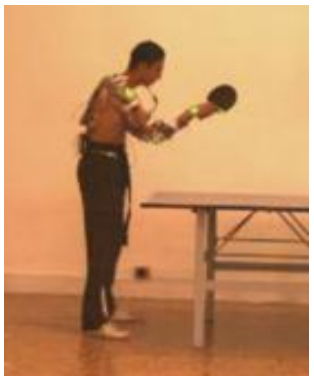

7

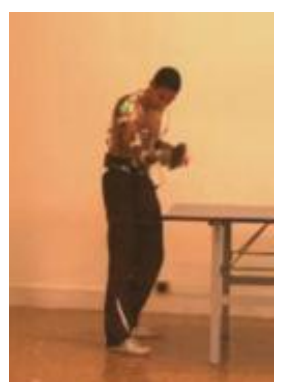

3

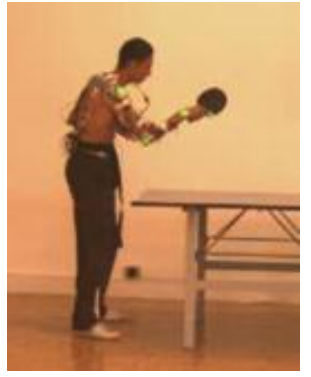

8

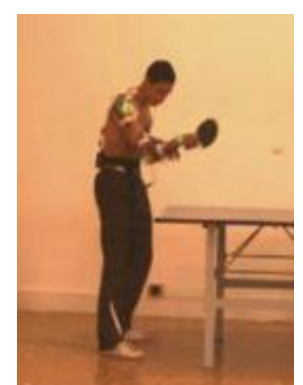

4

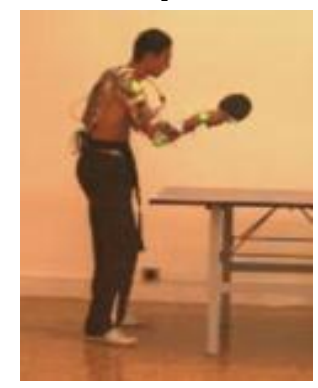

9

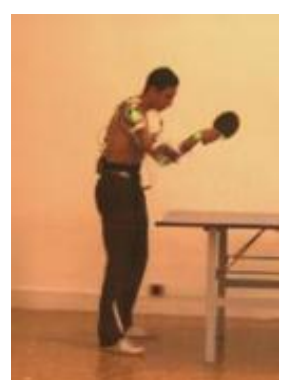

5

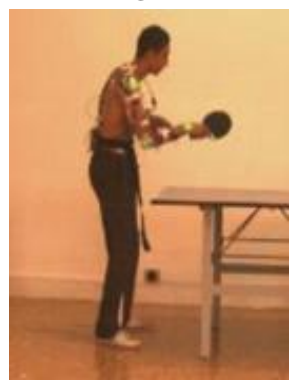

10

\section{Results}

The researcher verified the first hypothesis of the test that measures what it was designed for and it prefers between distinctive and less distinctive groups so it can be used in the assessment.

Table 1

The correlation factor between the biomechanical indicators of the center of gravity of the used arm in the smash stroke and the accuracy degree of the performance $(\mathrm{n}=12$ attempts $)$

\begin{tabular}{|c|c|c|}
\hline \multicolumn{2}{|c|}{ Biomechanical Indicators } & $\begin{array}{c}\text { Correlation } \\
\text { Factor }\end{array}$ \\
\hline \multirow{4}{*}{$\begin{array}{c}\text { Center of Gravity of } \\
\text { the Used Arm }\end{array}$} & $\mathrm{v} \_\mathrm{mag}[\mathrm{m} / \mathrm{s}]$ & $-0,640^{*}$ \\
\hline & a_mag $\left[\mathrm{m} / \mathrm{s}^{\wedge} 2\right]$ & $-0,629 *$ \\
\hline & mmntm_mag $[\mathrm{kg} \mathrm{m} / \mathrm{s}]$ & $-0,640 *$ \\
\hline & F_mag $[\mathrm{N}]$ & $-0,629 *$ \\
\hline
\end{tabular}

Correlation is significant at the 0.05 level $=0.553$ (two tail)

It's clear from the table (1) that there is a reverse relation between the resultant of the (velocity, acceleration, momentum, force ) of the center of gravity the used arm and the accuracy degree of the performance, which confirms that any decrease in velocity, acceleration and momentum at the moment of hitting the ball leads to an increase in the accuracy degree of directing the ball towards the hardest places on the opponent's side.

For the resultant force and its reverse relation with the accuracy level of performance; the researcher believes that the high levels players save their efforts. Also, we find that the player exerts the force in the right timing. (10:161) ( 2 :283)
The correlation factor between the angular biomechanical indicators of the center of gravity of the used arm in the smash stroke and the accuracy degree of the performance $(n=12$ attempts)

\begin{tabular}{|c|c|c|}
\hline \multicolumn{2}{|c|}{ Biomechanical Indicators } & Correlation Factor \\
\hline \multirow{3}{*}{ Elbow's Angle } & angle $[\mathrm{deg}]$ & $145,-0$ \\
\cline { 2 - 3 } & $\omega[\mathrm{deg} / \mathrm{s}]$ & $-0,646^{*}$ \\
\cline { 2 - 3 } & $\alpha\left[\mathrm{deg} / \mathrm{s}^{\wedge} 2\right]$ & $-0,644^{*}$ \\
\hline \multirow{3}{*}{ Angle's Elbow } & angle $[\mathrm{deg}]$ & $-0,636^{*}$ \\
\cline { 2 - 3 } & $\omega[\mathrm{deg} / \mathrm{s}]$ & $-0,643^{*}$ \\
\cline { 2 - 3 } & $\alpha\left[\mathrm{deg} / \mathrm{s}^{\wedge} 2\right]$ & $-0,638^{*}$ \\
\hline
\end{tabular}

Correlation is significant at the 0.05 level $=0.553$

It's clear from the table (2) that there is a reverse relation between the angular velocity and the angular acceleration of the elbow and the accuracy degree of the performance. There is a reverse relation between the angle, acceleration and velocity of the wrist and the accuracy degree of the performance. This confirms that the decrease in the angular acceleration and the angular velocity of the elbow and the wrist relatively at the moment of hitting the ball so as to ensure a high accuracy in directing the ball to achieve a direct point.

The angle of the elbow is complemented the motion where the momentum moves from the hand to the racket then to the ball. $(5: 267)$ The hitting skills aim to achieve a higher linear speed, at the end joint (remote joint of the arm) and these skills may use the racket in table tennis as an additional link. (2 : 194) 
Table 3

The correlation factor between the biomechanical indicators of the center of gravity of the ball in the smash stroke and the accuracy degree of the performance (at the moment of hitting the ball) ( $\mathrm{n}=12$ attempts)

\begin{tabular}{|c|c|c|}
\hline \multicolumn{2}{|c|}{ Biomechanical Indicators } & $\begin{array}{c}\text { Correlation } \\
\text { Factor }\end{array}$ \\
\hline \multirow{4}{*}{$\begin{array}{c}\text { Center of Gravity of } \\
\text { the Ball }\end{array}$} & v_mag [m/s] & 0,135 \\
\cline { 2 - 3 } & a_mag [m/s^2] & $-0,646^{*}$ \\
\cline { 2 - 3 } & $\begin{array}{c}\text { momentum_mag [kg } \\
\text { m/s] }\end{array}$ & 0,240 \\
\cline { 2 - 3 } & F_mag [N] & $-0,646^{*}$ \\
\hline
\end{tabular}

Correlation is significant at the 0.05 level $=0.553$

It's clear from the table (3) that there is an inverse relation between a_mag [m/s2] and the resultant force F_mag [N] amounted. The correlation factor reached -0.646 which confirms that decreasing the acceleration and the force at the moment of hitting the ball leads to a high accuracy degree of directing the ball on the different places on the table. No relation appears between the speed v_mag [m / $\mathrm{s}]$ and the momentum _mag show [ $\mathrm{kg} \mathrm{m} / \mathrm{s}]$ and the accuracy degree of directing the ball.

The researcher believes that the high level players have the experience to benefit from the dynamic force. The players can control the skill through controlling the working muscles of the upper arm part, which is the primary source of the main force, where this part is responsible for start the acceleration process of the used arm and it is consistent with the results of Amira Ahmad's study (2009) (1).
Force and Speed of the ball are the basis of the smash stroke to achieve points in the game. This is clear according to the following equation: $\mathrm{F}=\mathrm{ma}$

Where: $\mathrm{F}=$ force, $\mathrm{m}=$ mass, $\mathrm{a}=$ acceleration

According to the law of the acceleration, the force has a direct relation with the acceleration and a reverse one with the mass. This is consistent with the results of this study, where the tennis racket's mass has a reverse relation with the force.

The player hits the ball when it reached the farthest bounce distance with a big backswing for the racket. This generates a great force while hitting the ball in order to send the ball to a hard place on the table to make it difficult to return the ball. (3: 67.68)

The racket has a large kinetic energy transfers into the ball by increasing the length of the striking arm, where the transitional motion $=$ angular velocity $\times$ radius

The value of the calculated $\mathrm{T}$ of the differences between the two groups in the test of directing the ball is 4.839 and this value is significant at a level of 0.05 . The validity factor in the test is 0.868 . This confirms that accuracy test is discriminatory, and it measures what it was designed for.

\section{$\mathrm{V}=\mathrm{W} \times \mathrm{r}$}

Table 4

Meanings of the Simple Linear Regression for the linear Biomechanical Indicators of the center of gravity of the used

\begin{tabular}{|c|c|c|c|c|c|c|c|c|}
\hline $\begin{array}{c}\text { Biomechanical } \\
\text { Indicators }\end{array}$ & $\begin{array}{c}\text { Correlation } \\
\text { Factor } \\
\mathrm{R}\end{array}$ & $\begin{array}{c}\text { Chi } \\
\text { Square } \\
\mathrm{R} 2\end{array}$ & $\mathrm{R} 2$ & $\begin{array}{c}\text { Stepwise } \\
\text { Regression }\end{array}$ & $\begin{array}{c}\mathrm{T} \\
\text { Value }\end{array}$ & $\begin{array}{c}\mathrm{F} \\
\text { Value }\end{array}$ & $\begin{array}{c}\text { Constant } \\
\text { Standard } \\
\text { Error }\end{array}$ \\
\hline v_mag [m/s] & 0,640 & 0,410 & 40,971 & $-1,201$ & 3,908 & 15,270 & 9,175 & 0,125 \\
\hline a_mag [m/s^2] & 0,629 & 0,396 & 39,622 & $-0,213$ & 3,800 & 14,437 & 8,512 & 0,076 \\
\hline mmntm_mag [kg m/s] & 0,640 & 0,410 & 40,969 & $-0,360$ & 3,908 & 15,269 & 9,174 & 0,014 \\
\hline F_mag [N] & 0,629 & 0,396 & 39,623 & $-0,064$ & 3,800 & 14,438 & 8,512 & 0,088 \\
\hline
\end{tabular}

\section{Predictive equations}

a) $\hat{y}=a+b 1 \times 1$

$\hat{y}=$ The accuracy degree of performance through resultant of velocity

$\mathrm{a}=$ Constant

$\mathrm{b} 1=$ stepwise regression of resultant velocity

x $1=$ average of resultant of velocity

$\hat{y}=9.175+(-1.201) \times$ average $\mathrm{V}_{-}$mag b) $\hat{y}=a+b 2 \times 2$

$\hat{y}=8.512+(-0.213) \times$ average $a_{-}$mag

c) $\hat{y}=a+b 3 \times 3$

$\hat{y}=9.174+(-0.366) \times$ average mmntm_ mag $_{-}$

d) $\hat{y}=a+b 4 \times 4$

$\hat{y}=8.512+(-0.064) \times$ average $\mathrm{F}_{-}$mag

Also, it is clear that all statistical variables confirm on the effectiveness of the predictive equation. 
Table 5

Meanings of the Simple Linear Regression for the angular Biomechanical Indicators of the center of gravity of the used arm

\begin{tabular}{|c|c|c|c|c|c|c|c|c|c|}
\hline \multicolumn{2}{|c|}{$\begin{array}{l}\text { Biomechanical } \\
\text { Indicators }\end{array}$} & $\begin{array}{l}\text { Correlation } \\
\text { Factor } \\
\text { R }\end{array}$ & $\begin{array}{c}\text { Chi } \\
\text { Square } \\
\text { R2 }\end{array}$ & $\mathrm{R} 2$ & $\begin{array}{c}\text { Stepwise } \\
\text { Regression }\end{array}$ & $\mathrm{T}$ Value & F Value & Constant & $\begin{array}{l}\text { Standard } \\
\text { Error }\end{array}$ \\
\hline \multirow{2}{*}{$\begin{array}{c}\text { Elbow's } \\
\text { Angle }\end{array}$} & $\omega[\operatorname{deg} / \mathrm{s}]$ & 0,646 & 0,417 & 41,676 & $-0,0020$ & 3,965 & 15,720 & 8,035 & 0,001 \\
\hline & $\alpha\left[\mathrm{deg} / \mathrm{s}^{\wedge} 2\right]$ & 0,644 & 0,415 & 41,497 & $-0,0001$ & 3,950 & 15,605 & 7,961 & 0,000 \\
\hline \multirow{3}{*}{$\begin{array}{l}\text { Wrist's } \\
\text { Angle }\end{array}$} & angle [deg] & 0,636 & 0,405 & 40,506 & $-0,0562$ & 3,870 & 14,978 & 19,860 & 0,015 \\
\hline & $\omega[\mathrm{deg} / \mathrm{s}]$ & 0,643 & 0,413 & 41,333 & $-0,0030$ & 3,937 & 15,500 & 7,910 & 0,019 \\
\hline & $\alpha\left[\mathrm{deg} / \mathrm{s}^{\wedge} 2\right]$ & 0,638 & 0,407 & 40,714 & $-0,0001$ & 3,889 & 15,108 & 8,199 & 0,000 \\
\hline
\end{tabular}

Predictive equations

a) $\hat{y}=a+b 1 \times 1$

$\hat{y}=8.035+(-0.0020) \times$ average $\omega$ of elbow

b) $\hat{y}=a+b 2 \times 2$

$\hat{y}=7.961+(-0.0001) \times$ average $\alpha$ of elbow

c) $\hat{y}=a+b 3 \times 3$

$\hat{y}=19.860+(-0.0562) \times$ average angle of wrist

d) $\hat{y}=a+b 4 \times 4$

$\hat{y}=7.910+(-0.0030) \times$ average $\omega$ of wrist

e) $\hat{y}=a+b 5 \times 5$

$\hat{y}=8.199+(-0.0001) \times$ average $\alpha$ of wrist

Also, it is clear that all statistical variables confirm on the effectiveness of the predictive equation.

Table 6

Meanings of the Simple Linear Regression for the linear Biomechanical Indicators of the center of gravity of the ball in the Forehand smash stroke

\begin{tabular}{|c|c|c|c|c|c|c|c|c|}
\hline $\begin{array}{c}\text { Biomechanical } \\
\text { Indicators }\end{array}$ & $\begin{array}{c}\text { Correlation } \\
\text { Factor } \\
\mathrm{R}\end{array}$ & $\begin{array}{c}\text { Chi } \\
\text { Square } \\
\mathrm{R} 2\end{array}$ & $\mathrm{R} 2$ & $\begin{array}{c}\text { Stepwise } \\
\text { Regression }\end{array}$ & $\begin{array}{c}\mathrm{T} \\
\text { Value }\end{array}$ & $\begin{array}{c}\mathrm{F} \\
\text { Value }\end{array}$ & $\begin{array}{c}\text { Constant } \\
\text { Error }\end{array}$ & $\begin{array}{c}\text { Standard } \\
\text { Eror }\end{array}$ \\
\hline a_mag [m/s^2] & 0,646 & 0,417 & 41,709 & $-0,037$ & 3,968 & 15,742 & 9,823 & 0,009 \\
\hline F_mag $[\mathrm{N}]$ & 0,646 & 0,417 & 41,710 & $-15,032$ & 3,968 & 15,743 & 9,838 & 0,010 \\
\hline
\end{tabular}

\section{Predictive equations}

a) $\hat{y}=a+b 1 \times 1$

$\hat{y}=9.823+(-0.037) \times$ average a_mag of the ball

b) $\hat{y}=a+b 2 \times 2$

$\hat{y}=9.838+(-15.032) \times$ average $\mathrm{F}_{-}$mag of the ball

Gamal Aladdin (2007) referred that it is mostly used averages of biomechanical indicators that concluded from the performance analysis of upper level players to design a standard model in order to compare the performances of the low levels players. $(6: 66)$

The researcher believes that the concluded predictive equations are characterized by objectivity because they are not subjected to any personal provisions.

\section{Conclusions}

The proposed test is used to measure the accuracy of the degree of smash stroke in table tennis, and the concluded predictive equations are characterized by objectively. The biomechanical statistical model is a high predictive efficiency and accuracy predicting performance of the smash stroke in table tennis.

\section{Recommendations}

The researcher recommends that using the proposed test as a mean to train and assess the table tennis players on different strokes, and getting benefit from the predictive equations in selecting players, evaluation process and also for building specific exercises in light of biomechanical model.

\section{References}

1. Amira , I . (2009) . Identifying the Effectiveness of the Comparison Biomechanical Indicators of the Smash Stroke for Table Tennis Players with Different Levels. Unpublished PhD thesis, Alexandria University, Egypt , Faculty of Physical Education for Girls.

2. Arthur, C. (2008). Biomechanics analysis of fundamental human movements, human kinetics, U.S.A. 
3. Ashok, K. (2003). table tennis, DPH Sports series, discovery Publishing house, New Delhi, p.p.67,68.

4. Ellen, W. , \& Salwa , F. (2004) . Reference in Table Tennis - Educational - training. Alexandria, Egypt: knowledge Institution.

5. Grimshow , P. , \& Burden, A. (2007). Sport and exercise biomechanics Taylor \& Francis Group, is the academic division Cromwell Press LTD.

6. Jamal , A. (2007). Morphological Bases to Evaluate the Technical and Tactical level of the athletes. Alexandria, Egypt: Arab Center for Publishing.

7. Marinovic, W., Lizuka, C. ,\& Freudenheim, A. (2004) . Control of striking velocity by table tennis players, PMID
: 15648504 Pub Med-indexed for Medline, Universidad de saopaulo.

8. Mohammed, B. \&\& Khayraya , I. (2002) . Basic Principles of Bio-mechanics in the Field of Sports, Part I. Alexandria, Egypt: Knowledge Facility,.

9. Richard , M. (2009). table tennis steps to success Human Kinetics, U.S.A.

10. Sawsan, A. M. , \& et.al. (1977) . Biomechanics in the Field of Sports, Part I. Alexandria, Egypt: Knowledge House

11. Sobhy, H. (2004) . Measurement and Evaluation in Physical Education and Sports, part 1. Cairo, Egypt: sixth edition, Dar-El Fakr El Araby,. 